\title{
The diagnostic utility of FNAC in palpable lesions of breast at a tertiary care centre
}

\author{
Pandey $A^{1}$, Mishra K.B ${ }^{2}$, Gaur B.S ${ }^{3}$, Singh $R^{4}$ \\ ${ }^{1}$ Dr. Anubha Pandey, 3rd year Resident, ${ }^{2}$ Dr. K.B. Mishra, Professor \& Head, ${ }^{3}$ Dr. Bindu Singh Gaur, Professor, \\ ${ }^{4}$ Dr Roma Singh, Assistant Professor, all authors are affiliated with Department of Pathology, L.N. Medical College, \\ Bhopal, M.P, India.
}

Address for Correspondence: Dr. Anubha Pandey, E-mail: dranu65@gmail.com

\begin{abstract}
Background: Breast lumps constitute a significant proportion of surgical cases in both developed and developing countries. Fine Needle Aspiration Cytology (FNAC) is a simple, minimally invasive, cost effective, outpatient based and a rapid diagnostic method for breast lesions. The aim of the present study was to study the cytological spectrum, cytohistological correlation and diagnostic accuracy of aspiration cytology (FNAC) in palpable breast lesions. Material and Methods: This was a prospective study done in the department of Pathology, L.N. medical college, Bhopal, India from January 2016 to December 2016. FNAC of 300 cases of palpable breast lesions were done and reported by expert pathologist. The histopathological specimen when available were reported by other pathologist without prior knowledge. Sensitivity, specificity and accuracy of FNA diagnosis were then analyzed. Results: A total of 300 cases of breast lesion were diagnosed on FNA, out of them histopathological correlation was available for 150 cases. Benign breast lesions are more common in younger patients in 11-30 age group and Malignant breast lesion are more common in old age group patients of 41-60 yrs age group. Benign breast lesions were found in 215 cases $(71.66 \%)$; among which fibroadenoma $(41 \%)$ was the commonest lesion observed. Malignancy was observed in 63 cases $(21 \%)$; among them, Ductal carcinoma was the predominant lesion (17.66\%). The sensitivity, specificity and diagnostic accuracy of FNAC for malignant lesion is found to be $98.3 \%, 98.9 \%$ and $98.7 \%$ respectively. Conclusion: FNAC is an effective and valid tool as first line diagnostic modality in preoperative diagnosis of malignant and benign breast lesions.
\end{abstract}

Keywords: Breast lesion, FNAC, Benign, Malignant

\section{Introduction}

Breast lumps constitute a significant proportion of surgical cases in both developed and developing countries. Vast majority of them are in women and are benign. It is needed to distinguish benign lumps from malignant preoperatively for definite treatment $[1,2]$. Breast carcinomas are one of the leading causes of cancer in women. Fine Needle Aspiration Cytology (FNAC) is one of the important components of 'triple approach', which has been widely accepted for the preoperative diagnosis of breast lesions [3]. It is a multi-disciplinary approach that includes analysis of clinical and radiological findings in conjunction with FNAC features, to diagnose the breast lesions and to

Manuscript received: $10^{\text {th }}$ March 2017

Reviewed: $18^{\text {th }}$ March 2017

Author Corrected: $25^{\text {th }}$ March 2017

Accepted for Publication: $31^{\text {st }}$ March 2017 determine the best management plan for the patient. FNAC can reduce the number of open breast biopsies [4]. Scope of FNA has now extended into identifying the subtypes of benign, malignant lesions and residual disease for the purpose of planning the therapeutic protocol and eventual follow-up [5,6]. The present study was undertaken to study the cytological spectrum of breast lesions, to correlate cytological findings with histopathological findings and to determine the diagnostic accuracy of FNAC in the diagnosis of breast lesions of breast at a tertiary care centre.

\section{Materials and Methods}

This study was conducted in the Department of Pathology, L.N. Medical College, Bhopal M.P. A total 
of 300 cases were included in the study. The study was approved by the Medical Ethics Committee of L.N. Medical College and a written informed consent was taken from all the patients.

Study Period: A one year study period from January 2016 to December 2016.

Study Design: This was a prospective study on the patients attending surgery OPD with complaints of palpable breast lump.

Sample Size:-The sample size required for detecting the cyto-histopathological correlation in study population at $95 \%$ confidence level would be 150 cases.

\section{Inclusion Criteria}

1. Female patients presenting with palpable breast lump of variable duration.

2. Clinically stable patient.

\section{Exclusion Criteria}

1. Patients not willing (No informed consent).

2. Patients undergoing chemotherapy.

3. Frank malignant mass with skin infiltration.

Procedure: A written consent was taken from the patient along with detailed history. The breast was examined and palpated. The suspicious area was cleaned with antiseptic solution and spirit. The skin over the lump was stretched and multiple passes at different angles were taken with a 10 or $20 \mathrm{cc}$ syringe fitted with a $22 \mathrm{G}$ needle. The aspirated material was smeared on the glass slides and fixed as necessary. Few of them were air dried and stained by May Grunwald Giemsa (MGG) stain while wet fixed smears were stained with papanicoloau stains. In order to ensure uniformity in the diagnostic reporting, the National Cancer Institute (NCI) [7] has developed and recommended five categories for assessing and reporting of palpable breast lesions. The five categories for reporting of these lesions are: Inadequate smear (C1), benign (C2), suspicious probably benign (C3), suspicious probably malignant (C4) and malignant (C5).

Biopsy specimens were received in 150 cases. The surgical specimens received were evaluated grossly, and representative sections were taken. The tissue was fixed in $10 \%$ buffered formalin and then processed by automatic tissue processor (Yorco). Sections were cut at 4-5 microns thickness and stained with hematoxylin and eosin. The histopathological examination was carried out by pathologists without prior knowledge of cytodiagnosis.

Correlation between cytological and histological diagnosis were done and accuracy of diagnosis was assessed by calculating sensitivity, specificity, predictive values and diagnostic accuracy of FNAC.

\section{Results}

The age of the patients in the present study varied from 14 to 85 years. Only Female patients were included in the study. The maximum number of patients in the study population were young in the age group of 21-40 years. The maximum numbers of benign lesions were encountered in the age range of 11- 40 years whereas the malignant lesions noted in age range of 31- 60 years. This distribution shows that the likelihood of a breast lesion to be malignant increases, as the age advances. [Table -1]

Table-1: Distribution of benign and malignant cases according to age groups.

\begin{tabular}{|c|c|c|c|c|c|c|}
\hline $\begin{array}{c}\text { Age group } \\
\text { (in Yrs) }\end{array}$ & $\begin{array}{c}\text { No of cases } \\
\text { (Benign) }\end{array}$ & Percentage & $\begin{array}{c}\text { No. of cases } \\
\text { (Malignant) }\end{array}$ & Percentage & Total & Percentage \\
\hline $11-20$ & 51 & $17 \%$ & 0 & $0 \%$ & 51 & $17 \%$ \\
\hline $21-30$ & 65 & $21.66 \%$ & 4 & $1.33 \%$ & 69 & $23 \%$ \\
\hline $31-40$ & 69 & $23 \%$ & 14 & $4.66 \%$ & 83 & $27.66 \%$ \\
\hline $41-50$ & 37 & $12.33 \%$ & 16 & $5.33 \%$ & 53 & $17.66 \%$ \\
\hline $51-60$ & 5 & $1.66 \%$ & 13 & $4.33 \%$ & 18 & $6 \%$ \\
\hline $61-70$ & 5 & $1.66 \%$ & 16 & $5.33 \%$ & 21 & $7 \%$ \\
\hline Above 70 & 1 & $0.33 \%$ & 4 & $1.33 \%$ & 5 & $1.33 \%$ \\
\hline Total & 233 & $77.7 \%$ & 67 & $22.3 \%$ & 300 & $100 \%$ \\
\hline
\end{tabular}


Out of 300 cases, 147 cases (49\%) were in left breast, 126 cases (42\%) were in right breast, and 27 cases (9\%) presented bilaterally. Majority of the cases were seen in superolateral quadrant (163 cases) which was followed by 65 (21.66\%) cases in inferolateral quadrant. The superomedial and inferomedial quadrant comprised of $49(16.33 \%)$ and $17(5.66 \%)$ cases respectively. Lumps were subareolar in location in $4(1.33 \%)$ cases. The mass was diffuse and involved all the quadrants in 2 cases [Figure-1].

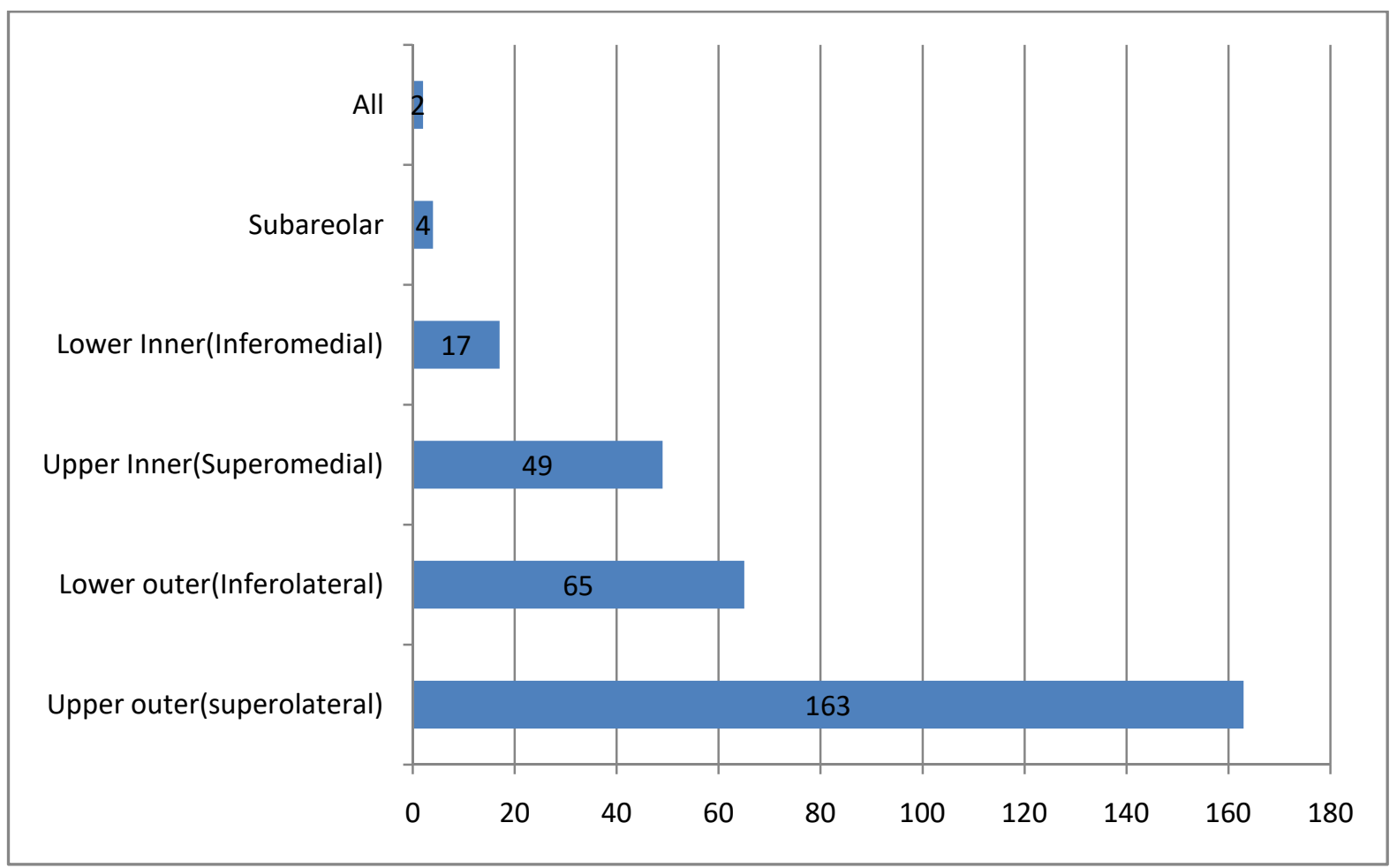

Fig-1: Anatomical distribution of lesions in both breasts (Quadrant-wise).

The aspirates were considered to be inadequate if only fat and fibrous tissue were aspirated, without any cellular material, even after repeat aspiration. Out of 300 cases, 215 were found to be Benign (C2) In C3 category we diagnosed 12 cases as benign with atypia comprising of cases of epithelial hyperplasia with atypia and fibroadenoma with atypia, $\mathrm{C} 5$ (malignant) category comprised of 63(21\%) cases , majority being ductal carcinoma. The cytological spectrum of various palpable breast lesions in the study is shown in Table-2.

Table-2: Cytological spectrum of breast lumps on FNAC.

\begin{tabular}{|c|c|c|}
\hline Cytological Diagnosis & No of cases & Percentage \\
\hline C1(Inadequate) & 6 & $2 \%$ \\
\hline C2(Benign) & 215 & $71.66 \%$ \\
\hline C3(Atypia probably benign) & 12 & $4 \%$ \\
\hline C4(Suspicious probably malignant) & 4 & $1.33 \%$ \\
\hline C5(Malignant) & 63 & $21 \%$ \\
\hline Total & 300 & $100 \%$ \\
\hline
\end{tabular}

The cytological spectrum of various benign breast lesions encountered in the present study shows that out of the total 215 cases $(71.66 \%)$ that could be satisfactorily labeled as benign in the present study, Fibroadenoma accounted for 123 cases, fibrocystic disease for 22 cases, Inflammatory lesions consist of 29 cases (9.66\%) with 11 cases of acute mastitis/ breast abscess and 10 cases of granulomatous mastitis. Frequency of benign breast lesion is tabulated in Table-3. 
Table-3: Distribution of Benign breast lesion.

\begin{tabular}{|c|c|c|c|}
\hline Category & Cytological Diagnosis & No. of Cases & $\begin{array}{c}\text { Percentage }(\%) \\
n=\mathbf{3 0 0}\end{array}$ \\
\hline \multirow{5}{*}{$\begin{array}{c}\text { Inflammatory Lesions } \\
\text { (29 Cases- } 9.66 \% \text { ) }\end{array}$} & Acute mastitis / Abcess & 11 & $3.66 \%$ \\
\hline & Granulomatous mastitis & 10 & $3.33 \%$ \\
\hline & Chronic mastitis (non-specific) & 4 & $1.33 \%$ \\
\hline & Duct ectasia & 2 & $0.66 \%$ \\
\hline & Fat necrosis & 2 & $0.66 \%$ \\
\hline \multirow{6}{*}{$\begin{array}{c}\text { Benign Breast Lesions } \\
(173 \text { Cases- } 57.66 \%)\end{array}$} & Fibroadenoma & 123 & $41 \%$ \\
\hline & Fibrocystic change & 22 & $7.33 \% \%$ \\
\hline & Fibroadenosis & 4 & $1.33 \%$ \\
\hline & Simple cyst & 4 & $1.33 \%$ \\
\hline & Epithelial hyperplasia & 15 & $5 \%$ \\
\hline & Galactocele & 5 & $1.66 \%$ \\
\hline $\begin{array}{l}\text { Lesion Not Recognizesd } \\
\text { As Benign or Malignant }\end{array}$ & Phyllodes tumor & 4 & $1.33 \%$ \\
\hline \multirow{2}{*}{$\begin{array}{c}\text { Atypical/Indeterminate- } \\
\text { Probably Benign (C3) } \\
(12 \text { case- } 4 \%)\end{array}$} & Epithelial hyperplasia with atypia & 4 & $1.33 \%$ \\
\hline & Fibroadenoma with atypia & 8 & $2.66 \%$ \\
\hline Miscellaneous & (Lipoma, Lactational changes) & 9 & $3 \%$ \\
\hline Inadequate/Inconclusive (C1) & & 6 & $2 \%$ \\
\hline Total & & 233 & $77.66 \%$ \\
\hline
\end{tabular}

On the other hand, 63 cases of malignant breast lesion were found in the study population. These cases were further studied for the histopathology. Infiltrating Ductal carcinoma (NOS) was the most common primary tumour diagnosed in 53 cases followed by 2 cases each of medullary \& lobular carcinoma. One case each of mucinous carcinoma, apocrine carcinoma and malignant phyllodes were also encountered in the study (Table 4). Out of 63 malignant cases, 34 cases showed metastatic tumor deposits in axillary lymph nodes.

\section{Table-4: Distribution of Malignant lesions.}

\begin{tabular}{|c|c|c|}
\hline Cytological diagnosis & No. of cases & Percentage $(n=300)$ \\
\hline Suspicious of malignancy $(\mathrm{C} 4)$ & 4 & $1.33 \%$ \\
\hline Ductal carcinoma in-situ $\quad$ (C5) & 3 & $1 \%$ \\
\hline IDC- NOS & 53 & $17.66 \%$ \\
\hline Medullary & 2 & $0.66 \%$ \\
\hline Mucinous & 1 & $0.33 \%$ \\
\hline Apocrine & 1 & $0.33 \%$ \\
\hline Lobular carcinoma & 2 & $0.66 \%$ \\
\hline Malignant phyllodes & 1 & $0.33 \%$ \\
\hline Total & 67 & $22.33 \%$ \\
\hline
\end{tabular}

Histopathological correlation was available in 150 cases. For calculation of statistical indices, the cases having unsatisfactory aspirates were excluded and suspicious cases were considered positive for malignancy, accounting to 150 cases. 148 cases correlated with cytological diagnosis and one case diagnosed benign on cytology proved to be malignant (infiltrating duct carcinoma-NOS type) on histology - False negative. One false positive case, which was benign proliferative breast disease- fibroadenoma with atypia by histology which was diagnosed as suspicious malignant lesion (IDC) on cytology (Table 5,6). The statistical analysis showed high sensitivity (98.3.\%) and specificity (98.9\%) of FNAC in breast lesions, with Positive Predictive Value (PPV) and the Negative Predictive Value (NPV) being $98.3 \%$ and $98.9 \%$ respectively. The diagnostic accuracy was found to be $98.7 \%$. 
Table-5: Statistical analysis.

\begin{tabular}{|c|c|c|c|}
\hline \multirow{2}{*}{ Cytological Diagnosis } & Histopathogical Diagnosis & \multirow{2}{*}{ Total } \\
\cline { 2 - 4 } & Malignant (positive) & Benign (negative) & 58 \\
\hline Positive for malignancy (Malignant) & $57(\mathrm{TP})$ & 1 (FP) & \\
\hline Negative for malignancy (Benign) & (a: true positive) & 91 (TN) & 92 \\
\hline Total & (c: false negative) & (d: true negative) & $\mathbf{1 5 0}$ \\
\hline
\end{tabular}

Table-6: Cytological and Histopathological correlation of non-neoplastic and neoplastic palpable breast lesion.

\begin{tabular}{|c|c|c|c|c|c|c|}
\hline \multirow[b]{2}{*}{ FNAC } & \multicolumn{5}{|c|}{ Histopathological Diagnosis } & \multirow[b]{2}{*}{$\stackrel{\bar{\pi}}{0}$} \\
\hline & 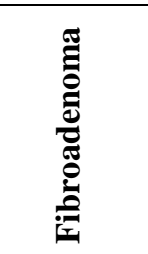 & 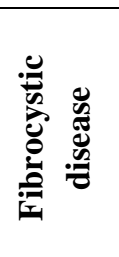 & 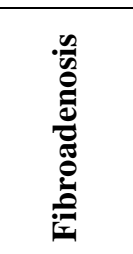 & 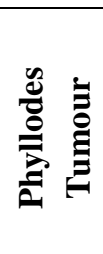 & שَّة & \\
\hline Fibroadenoma & $\begin{array}{c}79 \\
(52.7 \%)\end{array}$ & & & & & $\begin{array}{c}79 \\
(52.7 \%)\end{array}$ \\
\hline Fibrocystic change & & $\begin{array}{c}7 \\
(4.7 \%)\end{array}$ & & & & $\begin{array}{c}7 \\
(4.7 \%)\end{array}$ \\
\hline Fibroadenosis & & & $\begin{array}{c}2 \\
(1.3 \%) \\
\end{array}$ & & & $\begin{array}{c}2 \\
(1.3 \%) \\
\end{array}$ \\
\hline Galactocele & & & & & $\begin{array}{c}1 \\
(0.7 \%) \\
\end{array}$ & $\begin{array}{c}1 \\
(0.7 \%) \\
\end{array}$ \\
\hline PhyllodesTumour & & & & $\begin{array}{c}3 \\
(2 \%) \\
\end{array}$ & & $\begin{array}{c}3 \\
(2 \%) \\
\end{array}$ \\
\hline Suspicious of malignancy & $\begin{array}{c}1 \\
(0.7 \%)\end{array}$ & & & & $\begin{array}{c}3 \\
(2 \%)\end{array}$ & $\begin{array}{c}4 \\
(2.7 \%)\end{array}$ \\
\hline Carcinoma & & & & & $\begin{array}{c}54 \\
(36 \%) \\
\end{array}$ & $\begin{array}{c}54 \\
(36 \%) \\
\end{array}$ \\
\hline Total & $\begin{array}{c}\mathbf{8 0} \\
(\mathbf{5 3 . 3 \%}) \\
\end{array}$ & $\begin{array}{c}7 \\
(4.7 \%) \\
\end{array}$ & $\begin{array}{c}2 \\
(1.3 \%) \\
\end{array}$ & $\begin{array}{c}3 \\
(2 \%) \\
\end{array}$ & $\begin{array}{c}58 \\
(38.6 \%) \\
\end{array}$ & $\begin{array}{c}150 \\
(100 \%) \\
\end{array}$ \\
\hline
\end{tabular}

\section{Discussion}

FNAC of breast lumps is an accepted and established method for determining the natures of breast lumps with a high degree of accuracy [8,9]. Application of Fine Needle Aspiration (FNA) for the diagnosis of palpable breast masses was first introduced by Martin and Ellis in 1930 and since then, it has been established as an important tool in the evaluation of breast lesions [10]. In the present study, age of the patients ranged from 14-85 years.

The study population comprised of all female cases. In this study, maximum numbers of cytologically benign lesions were seen in the age group ranging from 14 to 40 years. This was similar to the findings by Khemka et al [11] and Rocha et al [12] who had maximum cytological benign cases in the age groups 15-44 years and 14-40 years respectively. Malignant lesions were common in the age groups 31-70 years in the present study, 35-84 years in the study by Khemka et al [10] and 41-75 years in the study by Rocha et al [12], So overall pattern of occurrence is as expected, with benign lesions were more common in younger age group and malignant lesions in older age group. Similar age-group distribution of benign and malignant cases was observed in studies done in Asian countries [13,14]. Higher age-group in western countries was attributed to higher life expectancy [15]. 
In the present study of 300 patients, $71.66 \%$ were benign cases (n-215) and malignant lesions were found in 21\% (n-63). Yeoh et al [16] studied 1533 breast masses on FNAC and found that 70.4\% cases were benign. Similarly, Malik et al [17] in his study of 1724 cases over a period of 20 years reported benign lesions in $72.97 \%$ and malignant lesions in $27.3 \%$ of cases. Similar results were obtained by Iyer et al [18] and Mayun et al [19]. It has been emphasized in the past that vast majority of the lesions in breast are benign. Fibroadenoma was the most frequently (n-123) diagnosed lesion on FNAC in the present study. Aslam et al [20] also documented fibroadenoma as the most common benign lesion (71.3\%) in their study. Out of 300 cases studied, 147 cases (49\%) were in left breast, 126 cases (42\%) were in right breast and 27 cases (9\%) presented bilaterally. Meena et al [15] Reddy and Reddy et al [21] and Clegg-Lamptey and Hodasi et al [22] also studied that palpable breast lesions were slightly more common on the left side. Among all four quadrants, Upper and outer (Superolateral) quadrant was the most commonly involved quadrant (54.33\%) in the present study with 163 cases. This is in agreement with the findings of various studies [12,15,21-23].

Breast cancer is the second most common cancer among Indian females next only to cervical cancer. In experienced hands, FNA is highly accurate diagnostic procedure with sensitivity and specificity over $95 \%$ for palpable breast lesions [24,25]. In the present study, 63 cases were positive for malignancy (21\%), among them 53 cases $(17.66 \%)$ were diagnosed as Ductal carcinoma (NOS). Singh A et al (26) also reported that invasive ductal carcinoma is the commonest breast malignancy. In the present study, there were 215 cases diagnosed under the benign category from which 92 cases were available for histological follow up. Out of these 92 confirmed cases, 91 cases were found to be benign while one case was found to be malignant (false negative case). One false negative case which was seen in the lactating female whose cytology was diagnosed as galactocoele, its further follow upon histopathology was found out to be infiltrating ductal carcinoma. The diagnosis of carcinoma breast on cytology during lactation is difficult as it may sometimes be presented as obstructed galactophoreic duct may be the reason of false negative diagnosis. Hypercellular lesions such as cellular fibroadenoma, proliferative breast disease, phyllodes tumor and post radiation induced atypical changes can have findings such as nucleomegaly, mild pleomorphism and presence of nucleoli which may sometimes erroneously report malignancy in benign lesions [27]. In the present study we found one false positive case, which was diagnosed as suspicious of malignancy (C4) on cytology which was later diagnosed on histopathology as fibroadenoma with atypia. So, considering histological diagnosis as the gold standard, we found that the sensitivity, specificity and diagnostic accuracy of FNAC to detect malignant cases was $98.3 \%, 98.9 \%$ and $98.7 \%$ respectively, which were quite comparable with the findings of other studies. (Table-7)

In this prospective study 150 cases were included for cytohistologic correlation with $92(61.3 \%)$ benign cases, 54 (36\%) malignant cases and $4(2.66 \%)$ cases reported as suspicious of malignancy. Among the benign cases fibroadenoma comprised the maximum cases (79) followed by breast carcinoma in 54 cases. In the present study, 4 cases which were cytologically diagnosed as lesions suspicious for malignancy, of which 3 were confirmed as malignant lesions on histopathological examination, however. 1 case was diagnosed as benign. Cytohistologic correlation was seen in $98.9 \%$ of benign cases and $75 \%$ in cases suspicious for malignancy. All the 54 cytologically diagnosed malignant cases were confirmed as malignant on subsequent histopathological examinations. So, in our study, a 100\% cyto-histopathological correlation was observed for malignant lesions.

Table-7: Comparison of overall diagnostic accuracy of FNAC in breast lesions.

\begin{tabular}{|c|c|c|c|c|c|c|}
\hline $\begin{array}{c}\text { S. } \\
\text { No }\end{array}$ & Study & $\begin{array}{c}\text { Sensitivity } \\
(\boldsymbol{\%})\end{array}$ & $\begin{array}{c}\text { Specificity } \\
(\boldsymbol{\%})\end{array}$ & $\begin{array}{c}\text { Positive } \\
\text { Predictive } \\
\text { value (\%) }\end{array}$ & $\begin{array}{c}\text { Negative } \\
\text { Predictive } \\
\text { value (\%) }\end{array}$ & $\begin{array}{c}\text { Accuracy } \\
(\%)\end{array}$ \\
\hline 01 & JF Silverman et al $^{[25]}(1989)$ & 96 & 100 & 100 & 98 & 99 \\
\hline 02 & M Sampat et al $^{[26]}(1991)$ & 96 & 100 & 100 & 89.5 & 97 \\
\hline 03 & Rocha et al $^{[27]}(1997)$ & 93.80 & 98.21 & 92.70 & 95.6 & 97.4 \\
\hline 04 & RGW Pinto et al ${ }^{[2]}(2004)$ & 97.8 & 100 & 100 & 98.6 & 99.1 \\
\hline 05 & Ashwin et al $^{[29]}(2015)$ & 96.97 & 100 & 100 & 98.63 & 99.1 \\
\hline 06 & Present Study & 98.3 & 98.9 & 98.3 & 98.9 & 98.7 \\
\hline
\end{tabular}




\section{Conclusion}

Fine-needle aspiration cytology is a patient friendly, easy, reliable, repeatable and simple diagnostic test. When performed by an expert pathologist, the diagnostic accuracy of FNAC is very high. A high sensitivity and a high positive predictive value proved that a positive FNAC in the breast means a definite diagnosis of the concerned pathology if compared with the final histology report. The high specificity and a high negative predictive value for malignancy illustrated the high accuracy of FNAC in the diagnosis of malignancy in the breast. Very importantly, a report negative for malignancy was highly accurate $(>98 \%)$ in predicting an absence of malignancy. Thus, we conclude that FNAC is a very important preliminary diagnostic test in palpable breast lumps. Adhering to the principle of Triple test, with the acquisition of technical, observational and interpretative skills will further enhance the diagnostic accuracy of lesions of the breast.

\section{Funding: Nil, Conflict of interest: None Permission of IRB: Yes}

\section{References}

1. Vaidyanathan L, Barnard K, Elnicki DM. Benign breast disease: when to treat, when to reassure, when to refer. Cleve Clin J Med. 2002 May;69(5):425-32.

2. Guray M, Sahin AA. Benign breast diseases: classification, diagnosis, and management. Oncologist. 2006 May;11(5):435-49.

3. Kocjan G, Bourgain C, Fassina A, Hagmar B, Herbert A, Kapila K, Kardum-Skelin I, KlobovesPrevodnik V, Krishnamurthy S, Koutselini H, Majak B, Olszewski W, Onal B, Pohar-Marinsek Z, Shabalova I, Smith J, Tani E, Vielh P, Wiener H, Schenck U, Schmitt F. The role of breast FNAC in diagnosis and clinical management: a survey of current practice. Cytopathology. 2008 Oct; 19 (5): 271-8.doi: 10.1111/j. 1365-2303. 2008. 00610.x.

4. Hindle WH, Payne PA, Pan EY. The use of fineneedle aspiration in the evaluation of persistent palpable dominant breast masses. Am J Obstet Gynecol. 1993 Jun;168(6 Pt 1):1814-8; discussion 1818-9.

5. Bhargava V, Jain M, Agarwal K, Thomas S, Singh S. Critical appraisal of cytological nuclear grading in carcinoma of breast and its correlation with ER/PR expression. J Cytol. 2008 Mar; 25 (1): 58-61.doi:10. $4103 / 0970-9371.42445$

6. Joshi A, Maimoon S. Limitations of fine needle aspiration cytology in subtyping breast malignancies- A report of three cases. J Cytol. 2007 Mar16;24(4):203-6. Doi:10.4103/0970-9371.41899

7. Guidelines for non-operative diagnostic procedures and reporting in breast cancer screening Non-operative Diagnosis Subgroup of the National Coordinating Group for Breast Screening Pathology NHSBSP Publication No 502001 June:50(2):20-23.

8. Böcker W, Moll R, Poremba C, Holland R, Van Diest PJ, Dervan P, Bürger H, Wai D, Ina Diallo R, Brandt B, Herbst H, Schmidt A, Lerch MM, Buchwallow IB. Common adult stem cells in the human breast give rise to glandular and myoepithelial cell lineages: a new cell biological concept. Lab Invest. 2002 Jun; 82 (6): 737-46.

9. Wiseman BS, Werb Z. Stromal effects on mammary gland development and breast cancer. Science. 2002 May 10;296(5570):1046-9.

10. Litherland JC. Should fine needle aspiration cytology in breast assessment be abandoned? Clin Radiol. 2002 Feb;57(2):81-4.

11. Khemka A, Chakrabarti N, Shah S and Patel V. Palpable breast lumps, fine-needle aspiration cytology versus histopathology:a correlation of diagnostic accuracy. The internet journal of surgery.2009 Dec 1; 18 (1): 1-7.

12. Rocha PD, Nadkarni NS, Menezes S. Fine needle aspiration biopsy of breast lesions and histopathologic correlation. An analysis of 837 cases in four years. Acta Cytol. 1997 May-Jun;41(3):705-12.

13. Ganiat O, Omoniyi-Esan G, Osasan S, Titiloye N, Olasode B. Cytopathological review of breast lesions in Ile-Ife Nigeria. The Internet J. of Third World Med.2008 Jan;8(1):10-25.

14. Hussain MT. Comparison of fine needle aspiration cytology with excision biopsy of breast lump. J Coll Physicians Surg Pak. 2005 Apr;15(4):211-4. 
15. Meena SP, Hemrajani DK, Joshi N. A comparative and evaluative study of cytological and histological grading system profile in malignant neoplasm of breast - An important prognostic factor. Indian J Pathol Microbiol. 2006 Apr; 49(2):199-202.

16. Yeoh GP, Chan KW. Fine needle aspiration of breast masses: an analysis of 1533 cases in private practice. Hong Kong Med J. 1998 Sep; 4 (3): 283288.

17. Malik R, Bharadwaj VK. Breast lesions in young females--a 20-year study for significance of early recognition. Indian J Pathol Microbiol. 2003 Oct; 46 (4): 559-62.

18. Iyer SP; Epidemiology of Benign Breast Diseases in females of child bearing age group.Bombay Hospital Jr., 2000 Jan; 42(1): 141-146.

19. Mayun AA, Pindija VH; Pattern of histopathological diagnosis of breast lesion in Gombe, Nigeria. Nigerian J Med., 2008 Apr; 17 (2): 159-162.

20. Aslam S, Hameed S, Afzal T, Hussain A. Correlation of FNAC and HistologicalDiagnosis in the Evaluation of Breast Lumps. JUMDC 2012 Jul-Dec; 3 (2): 1-7.
21. REDDY DG, REDDY CR. Carcinoma of the breast, its incidence and histological variants among South Indians. Indian J Med Sci. 1958 Apr;12(4):228-34.

22. Clegg-Lamptey J, Hodasi W. A study of breast cancer in korlebu teaching hospital: Assessing the impact of health education. Ghana Med J. 2007 Jun; 41(2):72-7.

23. Zuk JA, Maudsley G, Zakhour HD. Rapid reporting on fine needle aspiration of breast lumps in outpatients. J Clin Pathol. 1989 Sep;42(9):906-11.

24. Chaiwun B, Thorner P. Fine needle aspiration for evaluation of breast masses. Curr Opin Obstet Gynecol. $2007 \mathrm{Feb} ; 19(1): 48-55$.

25. Ariga R, Bloom K, Reddy VB, Kluskens L, Francescatti D, Dowlat K, Siziopikou P, Gattuso P. Fine-needle aspiration of clinically suspicious palpable breast masses with histopathologic correlation. Am J Surg. 2002 Nov;184(5):410-3.

26. Singh K, Sharma S, Dubey VK, Sharma PR.Role of FNAC in diagnosis of breast lumps. JK Science.2001 July-Sept; 3(3):126-128

27. Parker SH, Stavros AT, Dennis MA. Needle biopsy techniques. Radiol Clin North Am. 1995 Nov;33(6): 1171-86.

\section{How to cite this article?}

Pandey A, Mishra K.B, Gaur B.S, Singh R.The diagnostic utility of FNAC in palpable lesions of breast at a tertiary care centre. Int J Med Res Rev 2017;5(03):338-345 doi:10.17511/ijmrr. 2017.i03.20. 